\title{
Autoimmune Hypophysitis with Late Renal Involvement: A Case Report
}

\author{
Stefano Iuliano ${ }^{1}{ }^{1}$, Maria Carmela Zagari ${ }^{1}$, Margherita Vergine ${ }^{1}$, Alessandro Comi ${ }^{2}$, Michele Andreucci $^{3}$, \\ Gemma Patella $^{3}$, Stefania Giuliano ${ }^{2}$, Sandro La Vignera ${ }^{4}\left(\mathbb{D}\right.$, Antonio Brunetti ${ }^{3}\left(\mathbb{D}\right.$, Antonio Aversa $\left.{ }^{1} * \mathbb{(}\right)$ \\ and Emanuela A. Greco ${ }^{3}$
}

check for

updates

Citation: Iuliano, S.; Zagari, M.C.; Vergine, M.; Comi, A.; Andreucci, M.; Patella, G.; Giuliano, S.; La Vignera,

S.; Brunetti, A.; Aversa, A.; et al.

Autoimmune Hypophysitis with Late Renal Involvement: A Case Report.

Endocrines 2021, 2, 160-166. https:// doi.org/10.3390/endocrines2020016

Academic Editor: Sheerazed Boulkroun

Received: 14 May 2021

Accepted: 10 June 2021

Published: 17 June 2021

Publisher's Note: MDPI stays neutral with regard to jurisdictional claims in published maps and institutional affiliations.

Copyright: (C) 2021 by the authors Licensee MDPI, Basel, Switzerland. This article is an open access article distributed under the terms and conditions of the Creative Commons Attribution (CC BY) license (https:/ / creativecommons.org/licenses/by/ $4.0 /)$.
1 Department of Experimental and Clinical Medicine, Magna Graecia University of Catanzaro, 88100 Catanzaro, Italy; stefano.iuliano@studenti.unicz.it (S.I.); maricazagari@gmail.com (M.C.Z.); margherita.vergine@hotmail.it (M.V.)

2 Azienda Ospedaliero-Universitaria MaterDomini, Policlinico Universitario Germaneto, 88100 Catanzaro, Italy; nikcomi@libero.it (A.C.); stefania.giuliano@unicz.it (S.G.)

3 Department of Health Sciences, Magna Graecia University of Catanzaro, 88100 Catanzaro, Italy; andreucci@unicz.it (M.A.); gemmapatella@hotmail.it (G.P.); brunetti@unicz.it (A.B.); emanuela.greco@unicz.it (E.A.G.)

4 Department of Clinical and Experimental Medicine, University of Catania, 95123 Catania, Italy; sandrolavignera@unict.it

* Correspondence: aversa@unicz.it

\begin{abstract}
We report a case of a 50-year-old male admitted to the Endocrinology Unit because of persistent headaches, nausea, feeling tired, sudden weight loss, cold intolerance, decreased appetite, and lack of sex interest. Diagnostic workup showed a 6-millimeter pituitary tumor without signs of compression, and a condition of progressive panhypopituitarism. After 12 months of hormone replacement therapy, the patient was hospitalized because of sudden weight gain, periorbital-peripheral edema, severe dyslipidemia, hypertension, and proteinuria. Corticosteroid therapy was shifted from oral to continuous intravenous infusion, and once the diagnosis of "immune complex-mediated glomerulonephritis with mesangial deposits suggestive for membranoproliferative glomerulonephritis type IIIIgG4-positive" was made, the immunosuppressant mycophenolate (1500 mg/day) was started. After a 6-month follow-up, the complete resolution of renal symptoms was accompanied by the disappearance of a pituitary lesion and the patient was back to prior hormone replacement therapy. Autoimmune hypophysitis (AH) is a rare autoimmune inflammatory disease of the pituitary gland that can impair hormone secretion and function. IgG4-hypophysitis is rare and is usually associated with other IgG4-related diseases. Herein, we describe a rare case of AH associated with late renal disease, and without any other organ involvement.
\end{abstract}

Keywords: autoimmune hypophysitis; systemic lupus erythematosus; hypopituitarism; autoimmune disease; sexual dysfunction

\section{Introduction}

Hypophysitis is a chronic inflammation of the pituitary gland and has many clinical and radiological features common to other non-secreting sellar masses. Thus far, many classifications have been proposed to define hypophysitis. As summarized in Table 1, this classification is based on anatomic location, histological appearance, and etiology. Primary hypophysitis is the most common form. It can occur in isolation, or as part of a multisystemic disease (i.e., IgG-related systemic disease).

IgG4-related diseases are characterized by the infiltration of the lymphocytes and plasma cells in one or more tissues and organs, and elevated plasma IgG4 levels. Many sites may be targeted by IgG-4, including retroperitoneum, salivary glands, and others. The pathogenesis of IgG4-related disease is still debated, but plasma cell infiltration seems to play a major role [1]. IgG4-hypophysitis represents less than $5 \%$ of all hypophysitis and 
was firstly described in 2004 [2]. In 2011, a new diagnostic classification was proposed by Leporati and colleagues [3], based upon studies on IgG4 levels, pituitary MRI results, clinical response to glucocorticoids, and histological proof of IgG4 disease in another organ, and/or histological findings of a pituitary biopsy. An increase in IgG4-related hypophysitis has been reported since then [4].

Table 1. Classification of hypophysitis. Modified from Leporati et al. [3].

\begin{tabular}{|c|c|}
\hline \multirow{3}{*}{ Anatomic Location } & Adenohypophysitis \\
\hline & Neurohypophysitis \\
\hline & Panhypophysitis \\
\hline \multirow{5}{*}{ Histological Findings } & Lymphocytic \\
\hline & Granulomatous \\
\hline & Xanthomatous \\
\hline & Necrotizing \\
\hline & IgG4 plasmacytic \\
\hline \multirow{2}{*}{ Etiology } & Primary \\
\hline & Secondary to systemic diseases, immunomodulatory drugs or sellar involvement \\
\hline
\end{tabular}

In a recent review, the pituitary function was normal in only $1.2 \%$ of IgG4-related hypophysitis, whereas more than $50 \%$ of patients presented panhypopituitarism [5]. Clinical symptoms also include nausea, vomiting, cranial nerve impairments [6], polyuria, decreased libido, and headache [1], in addition to the possibility that extrasellar expansion of the gland, by affecting the optic chiasm, may lead to impaired peripheral vision in affected individuals.

Many different preparations and doses of steroids are currently used to supply adrenal function and to treat the pituitary mass. After glucocorticoid therapy, even IgG4 may decrease or remain stable after treatment [1].

\section{Patients and Methods}

\subsection{Hormonal Assessment}

A 50-year-old engineer, non-smoker, married man was admitted to the emergency room of our hospital for repeated episodes of headaches, asthenia, lethargy, disabling arthromyalgia, and hypoactive sexual desire with associated erectile dysfunction (ED).

A review of his past medical history did not reveal any disorder. There were no prior surgeries, accidents, nor blood transfusion reports. No known food or drug allergies. Moreover, patient did not take any drugs.

Severe hyponatremia (Na $115 \mathrm{mEq} / \mathrm{L}$ ) was detected and treated with a $3 \%$ hypertonic solution. The patient was discharged with the diagnosis of "hyponatremia of unknown origin" and a complete clinico-endocrinological evaluation was obtained at our Endocrinology Unit to assess all of the pituitary axis.

On endocrinological laboratory testing, TSH $(0.008 \mathrm{uIU} / \mathrm{mL}), \mathrm{fT} 4(0.6 \mathrm{ng} / \mathrm{dL}), \mathrm{ACTH}$ (3.7 pg/mL), FSH $(0.00 \mathrm{mIU} / \mathrm{mL})$, and $\mathrm{LH}(0.01 \mathrm{mIU} / \mathrm{mL})$ were below the lower limit of the normal range, with hypotestosteronemia $(95.3 \mathrm{ng} / \mathrm{dL})$ combined with dyslipidemia (total cholesterol $307 \mathrm{mg} / \mathrm{dL}$ ). No defects in the GHRH-GH-IGF1 (151.9 ng/mL) axis were suspected.

\subsection{Radiological Assessment}

During the first admittance to our Endocrinology Unit (week 0), radiological examinations were carried out.

Magnetic resonance imaging (MRI) of the pituitary gland was performed (Figure 1), indicating the "prevalence of the left part of the adenohypophysis, miming the presence of a non-secreting pituitary lesion of $6 \times 5 \mathrm{~mm}$ diameter, without compressive effects 
on the chiasmatic cistern". As previously reported in the literature, magnetic resonance findings could mimic the features of a pituitary mass with diffuse and homogeneous contrast enhancement of the anterior pituitary, but with delayed/absent enhancement in the posterior part of the pituitary gland [7].

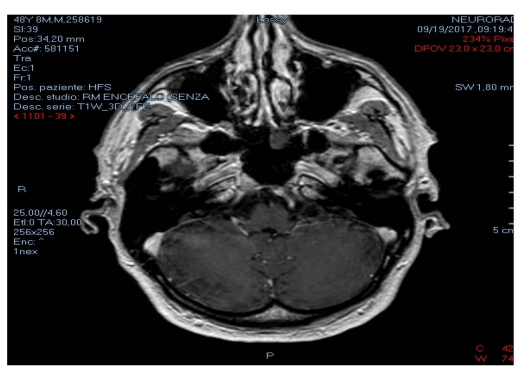

(a)

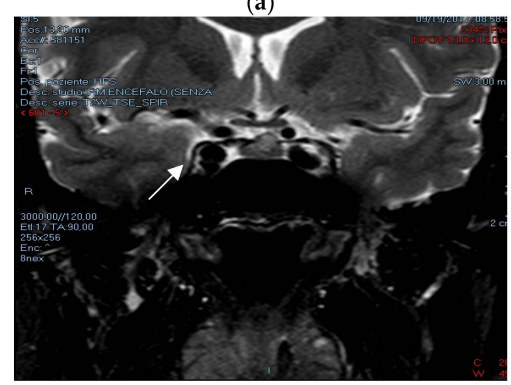

(d)

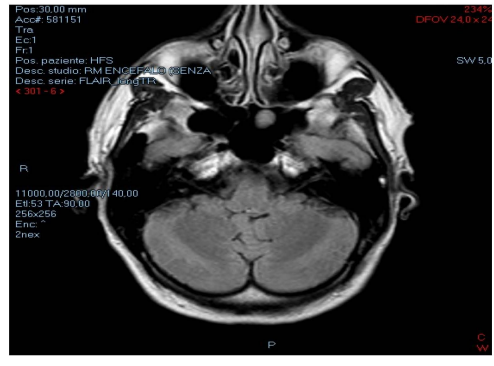

(b)

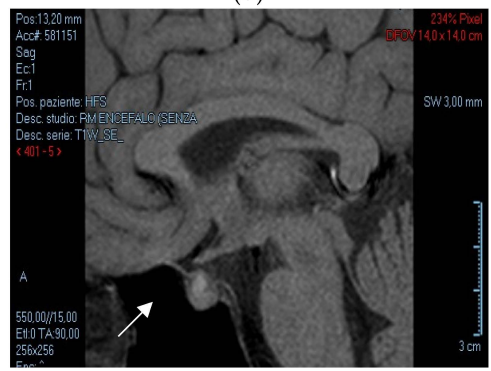

(e)

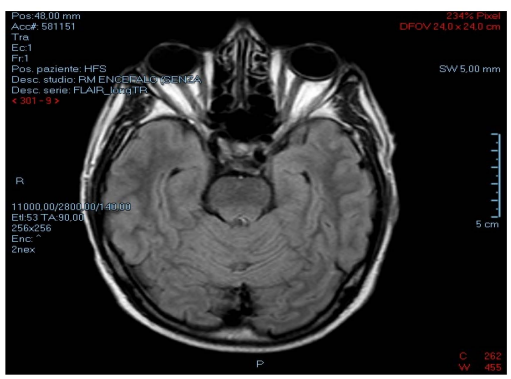

(c)

Figure 1. First MRI of pituitary gland performed at week 0 , showing the presence of a pituitary lesion in different sections (white arrow). (a-c) show sequential scans of the encephalic region, while (d,e) show pituitary gland interested by meoplasm.

Due to multiple hormonal deficiencies, the following therapy was started: cortisone acetate, $37.5 \mathrm{mg} /$ day; L-thyroxine, $50 \mathrm{mcg} /$ day, three weeks later; and, after six weeks, also testosterone gel, $20 \mathrm{mg} /$ day.

Since our patient suffered symptomatic hyponatremia (headache, cramps) from the beginning of his clinical history, to improve his sodium levels we decided to start fludrocortisone at a dose of $0.1 \mathrm{mg} /$ day. We attempted to withdraw it at established timepoints because of the nature of secondary adrenal insufficiency, but the recurrence of hyponatremia prompted us to reintroduce this drug.

Moreover, we introduced atorvastatin at a dose of $20 \mathrm{mg} /$ day due to dyslipidemia.

Due to the sudden onset of marked asthenia, headache, and insomnia (week 36), the patient was re-admitted to our Endocrinology Unit. Hormonal examination revealed low IGF1 levels; therefore, a GHRH-Arginine test was performed (peak GH $60 \mathrm{~min}=4.3 \mathrm{ng} / \mathrm{mL}$ ). Recombinant human GH ( $\mathrm{rhGH})$ therapy $(0.30 \mathrm{mg} /$ day) was started and a subjective clinical improvement in the reported initial symptoms appeared after 12 weeks [8,9]. Moreover, the L-thyroxine dosage was adjusted to $75 \mathrm{mcg} /$ day.

The most common causes (i.e., craniopharyngioma, traumatic brain injuries, apoplexia meningitis) were excluded due to patient's clinical history and MRI findings.

At week 48, the patient was hospitalized due to an acute onset of peripheral edema (lower limbs/periorbital), weight gain (+7 kg), and hypertension (blood pressure 160/100 $\mathrm{mmHg}$ ), which were successfully treated with a $100 \mathrm{mg} /$ i.v. of furosemide. Fludrocortisone treatment was withdrawn at admission, and i.v. methylprednisolone at a dose of $80 \mathrm{mg} /$ day was started instead.

Later on (week 60), a follow-up MRI (Figure 2) showed a normal size anterior pituitary gland and, the disappearance of the previously reported neoformation, without any sign of progressive atrophy or fibrosis [10]. 


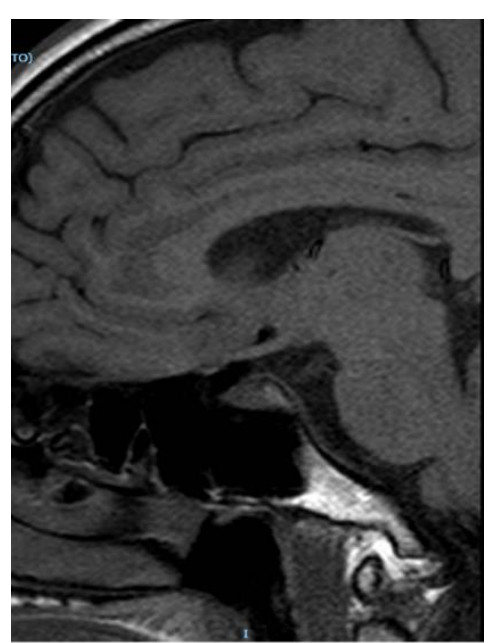

(a)

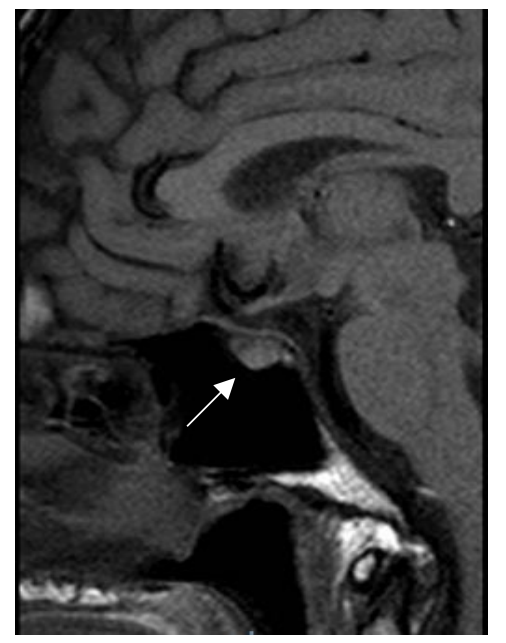

(b)

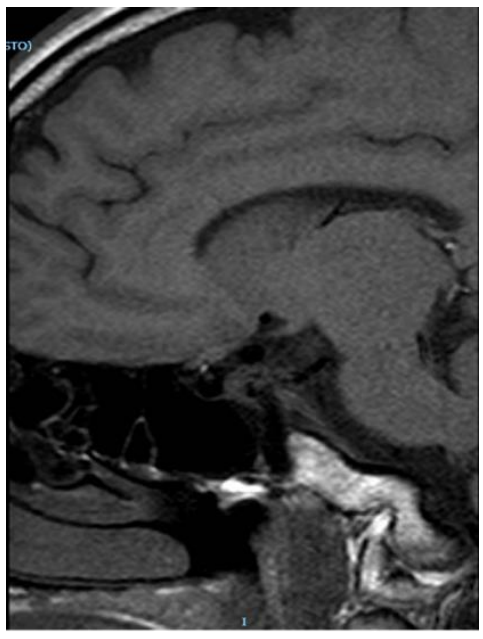

(c)

Figure 2. Follow-up MRI pituitary. Enhanced T1-weighted images showing disappearance of previously described pituitary lesion with normal stalk profile. $(\mathbf{a}-\mathbf{c})$ show sequential scan of the pituitary region previously interested by neoplasm.

\subsection{Nephrological Assessment}

All of the investigations were performed at week 48 , the timing of the onset of typical nephrological symptoms. Blood tests showed hyperuricemia $(9.20 \mathrm{mg} / \mathrm{dL})$, dyslipidemia (total cholesterol, $396 \mathrm{mg} / \mathrm{dL}$ ), hypoalbuminemia $(2.9 \mathrm{~g} / \mathrm{dL}$ ) and proteinuria $(5.3 \mathrm{~g} /$ day), normal serum electrolytes, hypocalciuria $(25 \mathrm{mg} /$ day), and hypernatriuria; plasmatic and urinary osmolality were within normal ranges. Creatinine was $1.32 \mathrm{mg} / \mathrm{dL}$, and eGFR $(76 \mathrm{~mL} / \mathrm{min})$ and azotemia $(31 \mathrm{mg} / \mathrm{dL}$ ) were within the normal ranges. On the basis of these results, the patient was then admitted to the Nephrology Unit of our hospital, where an abdominal ultrasound was performed (Report: regular thickness and echogenicity of the kidneys without stones or signs of urinary stasis).

Then a renal biopsy was performed (Histologic report: "Immune complex-mediated glomerulonephritis with mesangial deposits suggestive for membranous/membranoproliferative glomerulonephritis type III"; Figure 3). In addition, 6 renal glomeruli were positive for IgG3 and IgG4, using the Indirect Fluorescent-Antibody Technique. Low IgG1 and IgG2 levels and a decreased complement $\mathrm{C} 3$ component were found without positivity of Antiphospholipid/ANA/ENA antibodies.

While cortisone acetate was withdrawn, prednisone therapy was prescribed $(70 \mathrm{mg} /$ day $)$ along with mycophenolate, $500 \mathrm{mg} 3 \mathrm{cp} /$ day; ramipril, $5 \mathrm{mg} /$ day; alendronate, $70 \mathrm{mg} /$ week; calcitriol, $0.25 \mathrm{mcg} /$ day; and acetylsalicylic acid, $100 \mathrm{mg} /$ day were also started.

At week 72, the patient came back to our unit because of a regression in the swelling and normalization of blood pressure and other biochemical parameters. Therefore, prednisone and mycophenolate were gradually withdrawn, while cortisone acetate, at a dose of $37.5 \mathrm{mg} /$ day, was reintroduced. The L-thyroxine dosage was increased to $88 \mathrm{mcg} /$ day and testosterone gel was replaced by an undecanoate i.m. formulation. Fludrocortisone $(0.1 \mathrm{mg} /$ day) and rhGH $(0.30 \mathrm{mg} /$ day) therapies were continued. Finally, positivity to antidsDNA antibodies was found, while a repetition of the MRI scan confirmed the absence of any pituitary abnormality (data not shown).

At present, the 84-week follow-up has shown normal endocrine and renal parameters, and the patient does not complain of any symptoms. 


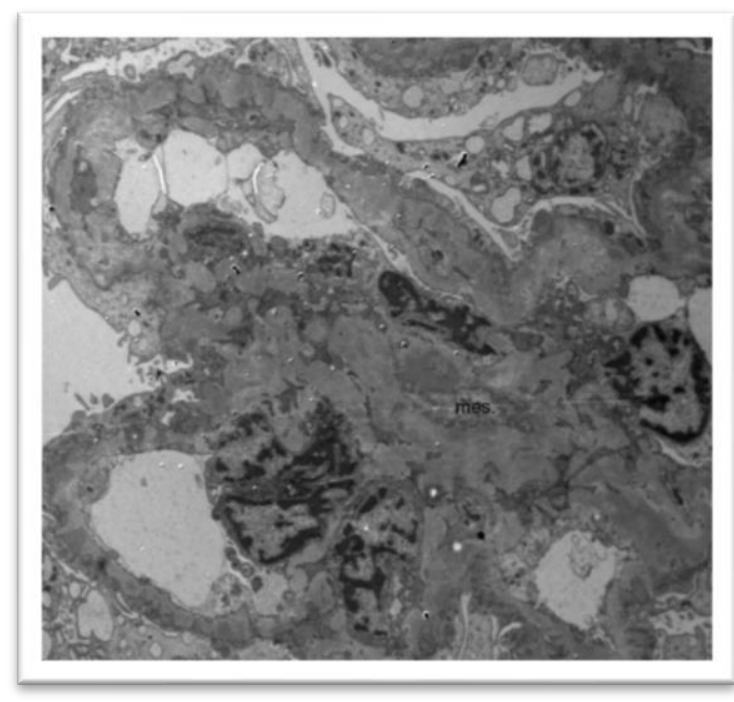

(a)

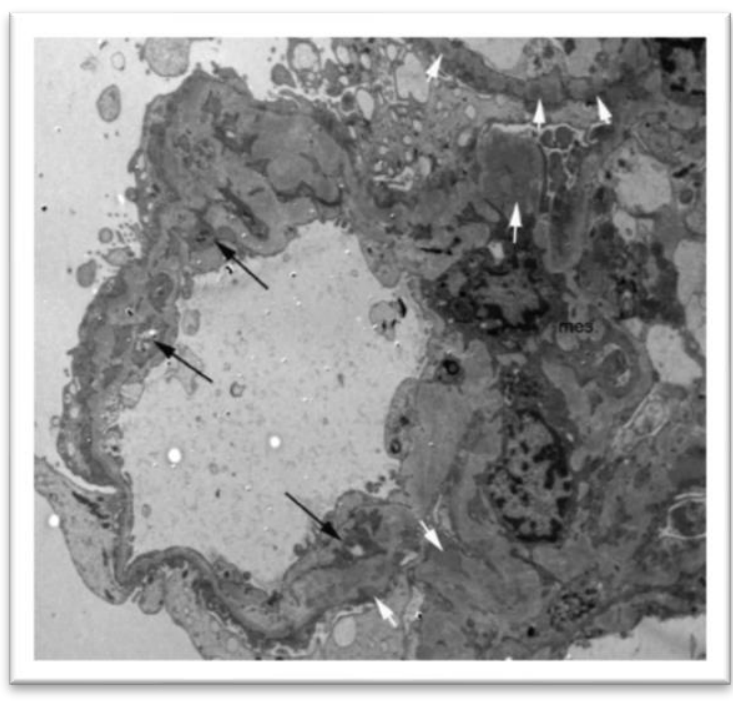

(b)

Figure 3. Renal biopsy (a) showing "Immune complex-mediated glomerulonephritis with mesangial deposits suggestive for membranous/membranoproliferative glomerulonephritis type III" (b); black and white arrows.

\section{Discussion}

As far as we are aware, this is the first report of $\mathrm{AH}$ in a patient with renal autoimmune involvement. At first, we had no clinical explanation for panhypopituitarism, other than the possibility of compressive lesions (not demonstrated by imaging) at the pituitary stalk. An explanation emerged once an autoimmune renal disease was diagnosed for this individual. As for other IgG4-related diseases, AH is characterized by the infiltration of the pituitary gland with numerous IgG4-producing plasma cells and lymphocytes. Therefore, as stated above, the visualization of cell infiltration in the pituitary gland is sufficient to establish the correct diagnosis (criterion 1, Figure 4). However, when a pituitary biopsy is not available, pituitary imaging (criterion 2, Figure 4) and IgG4 involvement in other organs (criterion 3, Figure 4) are also sufficient to establish a diagnosis. Otherwise, imaging (criterion 2), increased serum IgG4 levels (criterion 4), and a rapid response to glucocorticoids (criterion 5, Figure 4) can be used to diagnose IgG4-related $\mathrm{AH}$, according to criteria two, three, four, and five proposed by Leporati et al. (Figure 4) [3].

\begin{tabular}{|l|l|l|l|l|}
\hline $\begin{array}{c}\text { Pituitary } \\
\text { histopathology }\end{array}$ & MRI findings & $\begin{array}{c}\text { Involvement in } \\
\text { other organs } \\
\text { proved by biopsy }\end{array}$ & Serology & $\begin{array}{c}\text { Response to } \\
\text { glucocorticoid } \\
\text { therapy }\end{array}$ \\
\hline $\begin{array}{l}\text { Mononuclear } \\
\text { infiltration of } \\
\text { the pituitary } \\
\text { gland }\end{array}$ & $\begin{array}{l}\text { Sellar mass } \\
\text { and/or } \\
\text { thickened } \\
\text { pituitary stalk }\end{array}$ & $\begin{array}{l}\text { IgG4-positive } \\
\text { lesions }\end{array}$ & $\begin{array}{l}\text { High serum } \\
\text { IgG4 level } \\
(>140 \mathrm{mg} / \mathrm{dL})\end{array}$ & $\begin{array}{l}\text { Clinical and } \\
\text { radiological } \\
\text { improvement }\end{array}$ \\
\hline
\end{tabular}

Figure 4. Diagnostic criteria proposed by Leporati et al. [3], modified. Diagnosis is established when any of the following criteria are fulfilled: $1 ; 2+3 ; 2+4+5$.

As reported in a previous case of IgG4-related hypophysitis [11], the sequence of anterior hormone deficiency in our patient was as follows: gonadotropin $>\mathrm{ACTH}>$ TSH $>$ GH (no prolactin abnormalities). The possibility to withdraw any of the hormone substitution therapy was attempted, keeping in mind the negative MRI findings, but it was immediately ruled out because of the recurrent symptoms of panhypopituitarism. 
There is no standard glucocorticoid treatment regimen, but individualized treatment might improve prognosis [12]. In the present case, most of the patient's symptoms were resolved after glucocorticoid therapy, with a favorable effect on renal function and related clinical findings. Furthermore, the sellar mass completely disappeared 60 weeks later. At present, due to the lack of pituitary histology, we cannot provide any explanation for the beneficial effects of glucocorticoid plus immunosuppressive treatments on the pituitary tumor, but we are aware of their positive effects on the kidneys with a complete resolution of renal symptoms. The hormonal replacement therapy with testosterone gel completely resolved the patient's low sexual desire and ED [13], with reported satisfaction in the couple's relationship.

\section{Conclusions}

We report a single case of systemic IgG4-related disease, with an onset of manifestations at the pituitary gland and the late involvement of the kidneys. The diagnosis of IgG4-related AH may be difficult in the absence of renal involvement at the onset, but it should be considered as a possible clinical manifestation in patients with otherwise unexplained hypopituitarism and specific MRI findings (i.e., diffuse gland enlargement and/or a thickened pituitary stalk). Our data confirm a good prognosis for renal lesions, although with the persistence of pituitary hormone deficiencies and a need for multiple hormonal replacement therapies.

Author Contributions: Conceptualization, A.A., E.A.G., A.B. and S.L.V.; investigation, M.V., S.G., M.C.Z., A.C. and G.P.; writing-original draft preparation, S.I., M.V. and M.C.Z.; writing-review and editing, A.A., A.B. and S.L.V.; supervision, A.B., M.A. and A.A. All authors have read and agreed to the published version of the manuscript.

Funding: This research received no external funding.

Institutional Review Board Statement: Ethical review and approval were waived for this study, dealing with a case report conducted according to Clinical Practice guidelines.

Informed Consent Statement: Written informed consent for the publication of this case report was obtained from the patient. The study was performed in accordance with the Declaration of Helsinki.

Data Availability Statement: Data supporting the reported results are available from the corresponding author upon reasonable request.

Conflicts of Interest: The authors declare no conflict of interest.

\section{References}

1. Shimatsu, A.; Oki, Y.; Fujisawa, I.; Sano, T. Pituitary and stalk lesions (infundibulo-hypophysitis) associated with immunoglobulin G4-related systemic disease: An emerging clinical entity. Endocr. J. 2009, 56, 1033-1041. [CrossRef] [PubMed]

2. van der Vliet, H.J.; Perenboom, R.M. Multiple pseudotumors in IgG4-associated multifocal systemic fibrosis. Ann. Intern. Med. 2004, 141, 896-897. [CrossRef] [PubMed]

3. Leporati, P.; Landek-Salgado, M.A.; Lupi, I.; Chiovato, L.; Caturegli, P. IgG4-related hypophysitis: A new addition to the hypophysitis spectrum. J. Clin. Endocrinol. Metab. 2011, 96, 1971-1980. [CrossRef] [PubMed]

4. Lojou, M.; Bonneville, J.F.; Ebbo, M.; Schleinitz, N.; Castinetti, F. IgG4 hypophysitis: Diagnosis and management. Presse Med. 2020, 49, 104016. [CrossRef] [PubMed]

5. Shikuma, J.; Kan, K.; Ito, R.; Hara, K.; Sakai, H.; Miwa, T.; Kanazawa, A.; Odawara, M. Critical review of IgG4-related hypophysitis. Pituitary 2017, 20, 282-291. [CrossRef]

6. Joshi, M.N.; Whitelaw, B.C.; Carroll, P.V. MECHANISMS IN ENDOCRINOLOGY: Hypophysitis: Diagnosis and treatment. Eur. J. Endocrinol. 2018, 179, R151-R163. [CrossRef] [PubMed]

7. Sato, N.; Sze, G.; Endo, K. Hypophysitis: Endocrinologic and dynamic MR findings. Am. J. Neuroradiol. 1998, $19,439-444$. [PubMed]

8. Appelman-Dijkstra, N.M.; Claessen, K.M.; Roelfsema, F.; Pereira, A.M.; Biermasz, N.R. Long-term effects of recombinant human GH replacement in adults with GH deficiency: A systematic review. Eur. J. Endocrinol. 2013, 169, R1-R14. [CrossRef] [PubMed]

9. Koltowska-Häggström, M.; Mattsson, A.F.; Monson, J.P.; Kind, P.; Badia, X.; Casanueva, F.F.; Busschbach, J.; Koppeschaar, H.P.; Johannsson, G. Does long-term GH replacement therapy in hypopituitary adults with GH deficiency normalise quality of life? Eur. J. Endocrinol. 2006, 155, 109-119. [CrossRef] [PubMed] 
10. Cosman, F.; Post, K.D.; Holub, D.A.; Wardlaw, S.L. Lymphocytic Hypophysitis. Report of 3 New Cases and Review of the Literature. Medicine 1989, 68, 240. [CrossRef] [PubMed]

11. Li, Y.; Gao, H.; Li, Z.; Zhang, X.; Ding, Y.; Li, F. Clinical Characteristics of 76 Patients with IgG4-Related Hypophysitis: A Systematic Literature Review. Int. J. Endocrinol. 2019, 2019, 5382640. [CrossRef] [PubMed]

12. Lin, W.; Lu, S.; Chen, H.; Wu, Q.; Fei, Y.; Li, M.; Zhang, X.; Tian, X.; Zheng, W.; Leng, X.; et al. Clinical characteristics of immunoglobulin G4-related disease: A prospective study of 118 Chinese patients. Rheumatology 2015, 54, 1982-1990. [CrossRef] [PubMed]

13. La Viignera, S.; Izzo, G.; Emerenziani, G.P.; Cannarella, R.; Condorelli, R.A.; Calogero, A.E.; Aversa, A. Male hypogonadism: Therapeutic choices and pharmacological mangement. Minerva Endocrinol. 2020, 45, 189-203. [CrossRef] [PubMed] 